\title{
Foraging behaviour of Scymnus syriacus (Coleoptera: Coccinellidae) provided with Aphis spiraecola and Aphis gossypii (Hemiptera: Aphididae) as prey: Functional response and prey preference
}

\author{
Mahboobeh MORAdi, Mahdi hassanpour, Seyed Ali Asghar Fathi and Ali Golizadeh \\ Department of Plant Protection, Faculty of Agriculture and Natural Resources, University of Mohaghegh Ardabili, Ardabil, Iran; \\ e-mails: m.moradi@uma.ac.ir, hassanpour@uma.ac.ir, fathi@uma.ac.ir, golizadeh@uma.ac.ir
}

Key words. Coleoptera, Coccinellidae, Hemiptera, Aphididae, biological control, foraging behaviour, functional response, preference, switching, citrus

\begin{abstract}
Scymnus syriacus Marseul is one of the most important biocontrol agents of aphids in citrus orchards. Understanding the efficiency and host specificity of natural enemies can help improve their effectiveness as biological control agents of particular pests. In this study, the functional response, preference and switching behaviour of different stages of $S$. syriacus feeding on Aphis spiraecola Patch and Aphis gossypii Glover, on orange leaves, were studied under laboratory conditions of $27 \pm 2{ }^{\circ} \mathrm{C}, 65 \pm 5 \% \mathrm{RH}$ and a photoperiod of $16 \mathrm{~L}: 8 \mathrm{D}$. The results indicate that $4^{\text {th }}$ instar larvae and adult males and females of this predator exhibit a type II functional response when offered different numbers $(3,5,7,10,20,30,40,60$ and 80$)$ of both A.spiraecola and $A$. gossypii. Adult females had significantly higher attack rates (a) on both species of aphids. Handling times $\left(T_{h}\right)$ of adult male predators on $A$. spiraecola and those of $4^{\text {th }}$ instar larvae on $A$. gossypii were shorter than that of the other stages. In no-choice preference experiments, adult females fed equally on both species of aphid, but the $4^{\text {th }}$ instar larvae preferred $A$. gossypii. In switching experiments, prey selection was evaluated by simultaneously presenting different ratios $(30: 50,40: 40$ and $50: 30)$ of the two aphids, A. spiraecola: $A$. gossypii, to the predator. The $4^{\text {th }}$ instar larvae and adult females of $S$. syriacus showed higher preference for $A$. gossypii at each ratio offered (except adult females offered the $50: 30$ ratio). Based on their foraging behaviour $4^{\text {th }}$ instar larvae and adult females of $S$. syriacus are suitable for use in integrated management of citrus aphids.
\end{abstract}

\section{INTRODUCTION}

Citrus is a semi-tropical fruit crop with global availability and a popular component of human diets, which is grown in more than 140 countries (Liu et al., 2012). The most common citrus fruit with commercial importance are oranges, lemons, limes, grapefruit and tangerines (Liu et al., 2012; Loghmanpour Zarini et al., 2013). There are many species of aphids that can cause economic damage in citrus orchards (Rajabi, 1986). The citrus aphid, Aphis spiraecola Patch and the melon aphid, Aphis gossypii Glover (Hemiptera: Aphididae) are among the aphids that attack citrus trees, especially in the north of Iran (Soroushmehr et al., 2008; Tena \& Garcia-Mari, 2011; Alizadeh Kafeshani et al., 2018). Adults and immatures of these aphids can cause direct damage, especially to young citrus plantations by feeding on phloem sap. During feeding they inject saliva, which is phytotoxic and adversely affects the physiology of the trees. Furthermore, growth of sooty mould on aphid honeydew on leaves hinders their photosynthesis (Blackman \& Eastop, 2000; Garzo et al., 2002). Both of these species of aphids also cause indirect damage by transmitting important viruses (Blackman \& Eastop, 2000), such as
Citrus tristeza closterovirus (Closterovirus: Closteroviridae) (Ayazpour et al., 2013). Chemical control is the main method used to control citrus aphids (Smaili et al., 2014). However, excessive use of insecticides reduces natural enemy populations and leads to resistance of the aphids to many common insecticides. Biological control is a safe alternative method for controlling aphids in citrus orchards (Alizadeh Kafeshani et al., 2018).

Scymnus syriacus Marseul (Coleoptera: Coccinellidae) is a widely distributed species and is important in suppressing aphid abundance in citrus orchards (Allawi, 2006). Both larvae and adults actively search for leaves infested with aphids. They feed on many species of aphids, especially A. spiraecola and A. gossypii (Emami et al., 2004). The young larvae of $S$. syriacus usually suck out the contents of aphids, whereas adults eat the whole body of the aphids. The number of aphids consumed depends on the size of the aphid, developmental stage of the predator and environmental conditions, such as temperature. The mean number of aphids consumed by the larval stages of $S$. syriacus has reported to be 95 and 130 aphids at $25^{\circ} \mathrm{C}$ and $30^{\circ} \mathrm{C}$, respectively (Allawi, 2006). 
For the successful biological control of pests, it is necessary to understand the foraging behaviour of the natural enemies in terms of their functional response, prey preference and switching between prey (Heidarian et al., 2012; Rezaei et al., 2019). Functional response is the number of prey eaten per predator as a function of prey density (Jervis $\&$ Kidd, 1996). Holling (1959) categorized the functional response into three different types: a linear relationship between prey density and the number of prey consumed (type I), a curvilinear relationship (type II), and a sigmoidal relationship (type III). Other types of functional response, such as a dome-shaped response (type IV) and negative exponential response (type V) were reported by other researchers (Luck, 1985; Sabelis, 1992). Among these five types of functional response, type II and type III have received the most attention. Two important parameters: attack rate $(a)$ and handling time $\left(T_{h}\right)$ can be evaluated using functional response models. Natural enemies with high attack rate $(a)$ and low handling time $\left(T_{h}\right)$ are considered to be the most effective biocontrol agents (Bayoumy, 2011; Tazerouni et al., 2016).

Generalist predators may show prey preferences when foraging in patches containing more than one species of prey patches (Jaworski et al., 2013). Knowledge of the prey preferences of a predator is important for determining its predatory efficiency in situations in which various pests are present (Enkegaard et al., 2001). The tendency of a predator to choose one prey species over another may change as the relative densities of the species change (Murdoch, 1969). This behavioural trait is known as switching. Switching has a crucial role in extending the persistence of predator-prey systems (Van Baalen et al., 2001). In positive switching, a predator's preference for a specific prey increases as a function of the abundance of the prey, which could influence the stability of the prey populations. In negative switching, the predator's preference for a prey declines as a function of the abundance of this prey, and may destabilize trophic interactions by increasing the mortality of the species of prey whose density is decreasing (Murdoch, 1969; Chesson, 1984; van Baalen et al., 2001). Not all predators show switching behaviour (Chesson, 1984).

Since different types of prey have a critical effect on the foraging behaviour of predators, the present study was designed to evaluate the interactions of $S$. syriacus with two species of aphids, A. spiraecola and A. gossypii. Thus, in the current research the functional response, prey preference and switching of $S$. syriacus between $A$. spiraecola and $A$. gossypii reared on the leaves of orange, Citrus sinensis L., were investigated in order to assess the potential efficiency of this predator for controlling the abundance of aphids on citrus trees as a part of an IPM program.

\section{MATERIALS AND METHODS}

The initial populations of $S$. syriacus and the two species of prey, A. gossypii and A. spiraecola, were collected from unsprayed citrus orchards near Gaemshahr $\left(36^{\circ} 27^{\prime} 47^{\prime \prime} \mathrm{N}, 52^{\circ} 51^{\prime} 36^{\prime \prime} \mathrm{E}\right)$, Mazandaran province, Iran. The aphids were reared on the buds of young orange trees for several generations.
The stock culture of the predator was maintained on orange leaves (C. sinensis cv Thomson) infested with A. spiraecola or A. gossypii in plastic containers $(9 \times 10 \times 21 \mathrm{~cm})$ for three generations. In experiments that involved $S$. syriacus and one aphid species (functional response and no choice experiments), S. syriacus was reared on that aphid species. In experiments that involved S. syriacus and both aphid species (switching and choice experiments), the adaptation of $S$. syriacus to one species was avoided by rearing it on a mixed diet of an equal number of both species of aphids.

The experiments were conducted in Petri dishes $(9 \mathrm{~cm}$ in diameter). Each dish had a hole ( $2 \mathrm{~cm}$ in diameter) in the lid, which was covered by fine-mesh net for ventilation and its bottom lined with a layer of solidified agar solution $(2 \%)$ as a substrate to prevent orange leaves (C. sinensis $c v$. Thomson; $16.5 \mathrm{~cm}^{2}$ ) from desiccating. The Petri dishes were sealed with parafilm to prevent the escape of insects. All insect cultures and experiments were carried out in a growth chamber at $27 \pm 2{ }^{\circ} \mathrm{C}, 65 \pm 5 \% \mathrm{RH}$ and a photoperiod of 16L: 8D.

\section{Functional response experiment}

This experiment was conducted with $4^{\text {th }}$ instar larvae and adults (males and females less than $24 \mathrm{~h}$ old) of $S$. syriacus and a mixture of $3^{\text {rd }}$ and $4^{\text {th }}$ instar nymphs of $A$. spiraecola or A. gossypii. The predators were starved for $24 \mathrm{~h}$ prior to the experiments by placing them individually in Petri dishes devoid of prey. Different numbers $(3,5,7,10,20,30,40,60$, and 80$)$ of aphids were separately offered to the different stages of the predator. After 24 $\mathrm{h}$, the number of aphids eaten by the predator was recorded. For each prey density and predator stage, the experiment was replicated 10 times without prey replacement.

\section{Prey preference}

In this study, we preferentially selected the $4^{\text {th }}$ instar larvae and adult females of $S$. syriacus to study their preference and switching between $A$. spiraecola and $A$. gossypii, because they are more voracious than adult males (Omkar \& Kumar, 2013).

\section{No-choice experiment}

In the no-choice preference assay, 1-day-old $4^{\text {th }}$ instar larvae and females of $S$. syriacus, which were starved for $24 \mathrm{~h}$, were used. A mixture of eighty $3^{\text {rd }}$ and $4^{\text {th }}$ instar nymphs of $A$. spiraecola or $A$. gossypii were exposed to $4^{\text {th }}$ instar larvae and adult females of S. syriacus. After $24 \mathrm{~h}$, predators were removed from the arenas and the number of prey consumed was recorded. The experiment was replicated 10 times.

Independent $t$-test was used to test the significant difference between the predation rates of the predator of two species of prey (SPSS, 2007).

\section{Choice experiment and switching}

Switching behaviour of 1-day-old $4^{\text {th }}$ instar larvae and adult females of $S$. syriacus was investigated at different densities of $A$. spiraecola or $A$. gossypii (mixture of $3^{\text {rd }}$ and $4^{\text {th }}$ instar nymphs). The predators were starved for $24 \mathrm{~h}$ before the test. A. spiraecola: A. gossypii ratios presented to the predators were $30: 50$, $40: 40$ and $50: 30$. After $24 \mathrm{~h}$, each predator was removed from the arena and the number of prey consumed was recorded. There were 10 replicates for each ratio of prey and developmental stage of predator.

\section{Statistical analyses}

Statistical analysis of functional responses followed Juliano's (2001) approach. First, the type of functional response was determined using a logistic regression of the proportion of prey eaten 
$\left(N_{e}\right)$ as a function of prey offered $\left(N_{0}\right)$. This is done by fitting a polynomial function:

$$
\frac{N_{e}}{N_{0}}=\frac{\exp \left(P_{0}+P_{1} N_{0}+P_{2} N_{0}^{2}+P_{3} N_{0}^{3}\right)}{1+\exp \left(P_{0}+P_{1} N_{0}+P_{2} N_{0}^{2}+P_{3} N_{0}^{3}\right)}
$$

where $P_{0}, P_{1}, P_{2}$ and $P_{3}$ are the intercept, linear, quadratic and cubic coefficients, respectively. These coefficients were estimated using the method of maximum likelihood. If $P_{1}<0$, the proportion of prey eaten declines monotonically with the initial number of prey offered, which indicates a type II functional response (Juliano, 2001). If $P_{1}>0$ and $P_{2}<0$, the proportion of prey eaten is initially positively dependent on the density and consequently indicates a type III functional response. After determining the type of functional response, the handling time $\left(T_{h}\right)$ and attack rate $(a)$ were calculated using Rogers random predator equation (Rogers, 1972) as follows:

$N_{e}=N_{0}\left\{1-\exp \left[a\left(T_{h} N_{e}-T\right)\right]\right\}$

where $N_{e}$ is the number of prey eaten, $N_{0}$ is the initial prey density, $a$ is the attack rate, $T_{h}$ is the handling time and $T$ is the duration of the experiment. Pairwise comparisons of parameters of the functional responses for different larval instars or type of prey were performed using the indicator variable method (Juliano, 2001) as follows:

$N_{a}=N_{o}\left\{1-\exp \left[-\left(a+D_{a}(j)\right)\left(T-\left(T_{h}+D_{T h}(j)\right) N_{a}\right)\right]\right\}$

where $j$ is an indicator variable that has a value of 0 for the first data set and 1 for the second data set. The parameters $D_{a}$ and $D_{T h}$ estimate the differences between the data sets being compared for the values of the parameters $a$ and $T_{h}$, respectively. In other words, the handling time for one stage is $T_{h}$, and that for another stage is $T_{h}+D_{T h}$. Testing for a significant difference in handling times between two stages is accomplished by testing the null hypothesis that $D_{T h}$ includes 0 (Juliano, 2001).
The maximum predation rate $\left(T / T_{b}\right)$, which is the maximum number of prey that can be consumed by a predator during $24 \mathrm{~h}$, was calculated using the estimated $T_{h}$ (Hassell, 2000).

Prey preferences exhibited by $4^{\text {th }}$ instar larvae and adult females of S. syriacus were analysed by calculating Manly's index of preference (Manly, 1974). The index was calculated using the following formula:

$$
\beta_{1}=\frac{\log \left(\frac{e_{1}}{A_{1}}\right)}{\log \left(\frac{e_{1}}{A_{1}}\right)+\log \left(\frac{e_{2}}{A_{2}}\right)}
$$

where $\beta_{1}$ (Beta $=$ Manly's preference index) is the preference for a particular prey, $e_{1}$ and $e_{2}$ are the number of type 1 and 2 prey remaining at the end of the experiment, respectively, and $A_{1}$ and $A_{2}$ are the number of type 1 and 2 prey offered, respectively. The value of the index falls between 0 and 1 . An index close to 1 indicates strong preference for prey type 1 and a value equal to 0.5 indicates that the predator selects prey randomly and does not show any preference. Paired $t$-test was used to test the significance of Manly's index (SPSS, 2007). It is appropriate to use this index for assays in which prey species are offered simultaneously and are not replaced during the experiment (Manly et al., 1972). To compare the number of prey eaten by each stage of predator at the mentioned ratios, one-way ANOVA followed by Tukey $(p<$ 0.05 ) test was used (SPSS, 2007). Paired $t$-test was used to compare the number of prey eaten by each stage of predator in each combination. To test the significant difference between observed (number of prey eaten) and expected values for each prey ratio, Chi-square test was used. Furthermore, to evaluate the capacity of $S$. syriacus to switch between A. spiraecola and A. gossypii, the $\beta$-values were fitted to Manly's linear model for frequency dependent selection (Manly et al., 1972; Manly, 1973) as well as to non-linear models.

Table 1. Maximum likelihood estimates from the logistic regression analysis of the proportion of Aphis spiraecola

\begin{tabular}{|c|c|c|c|c|c|c|}
\hline Prey & Predator stage & Parameters & Estimate & SE & $x^{2}$ & $p$-value \\
\hline \multirow[t]{12}{*}{ A. spiraecola } & \multirow[t]{4}{*}{$4^{\text {th }}$ instar } & Constant & 0.9500 & 0.2368 & 16.09 & $<0.0001$ \\
\hline & & Linear & -0.0182 & 0.0215 & 0.72 & 0.3973 \\
\hline & & Quadratic & 0.000043 & 0.00054 & 0.01 & 0.9379 \\
\hline & & Cubic & $-4.52 \mathrm{E}-7$ & 4.023E-6 & 0.01 & 0.9106 \\
\hline & \multirow[t]{4}{*}{ Female } & Constant & 3.0138 & 0.3677 & 67.17 & $<0.0001$ \\
\hline & & Linear & -0.1016 & 0.0288 & 12.46 & 0.0004 \\
\hline & & Quadratic & 0.00122 & 0.000675 & 3.25 & 0.0714 \\
\hline & & Cubic & $-5.58 \mathrm{E}-6$ & 4.719E-6 & 1.40 & 0.2373 \\
\hline & \multirow[t]{4}{*}{ Male } & Constant & 0.2400 & 0.2230 & 1.16 & 0.2818 \\
\hline & & Linear & -0.0228 & 0.0205 & 1.24 & 0.2661 \\
\hline & & Quadratic & 0.00078 & 0.000529 & 2.15 & 0.1422 \\
\hline & & Cubic & $-4.968 \mathrm{E}-6$ & $3.9 \mathrm{E}-6$ & 1.62 & 0.2027 \\
\hline \multirow[t]{12}{*}{ A. gossypii } & \multirow[t]{4}{*}{$4^{\text {th }}$ instar } & Constant & 1.1963 & 0.2401 & 24.83 & $<0.0001$ \\
\hline & & Linear & -0.0481 & 0.0215 & 4.98 & 0.0257 \\
\hline & & Quadratic & 0.00025 & 0.00054 & 0.21 & 0.6466 \\
\hline & & Cubic & $1.541 \mathrm{E}-6$ & 4.02E-6 & 0.15 & 0.7015 \\
\hline & \multirow[t]{4}{*}{ Female } & Constant & 3.4145 & 0.4272 & 63.89 & $<0.0001$ \\
\hline & & Linear & -0.0936 & 0.0323 & 8.91 & 0.0028 \\
\hline & & Quadratic & 0.000847 & 0.00073 & 1.32 & 0.2513 \\
\hline & & Cubic & $-2.55 \mathrm{E}-6$ & 5.077E-6 & 0.25 & 0.6157 \\
\hline & \multirow[t]{4}{*}{ Male } & Constant & 3.3994 & 0.3949 & 74.12 & $<0.0001$ \\
\hline & & Linear & -0.1311 & 0.0303 & 18.74 & $<0.0001$ \\
\hline & & Quadratic & 0.00187 & 0.0007 & 7.10 & 0.0077 \\
\hline & & Cubic & $-9.77 \mathrm{E}-6$ & 4.85E-6 & 4.05 & 0.0442 \\
\hline
\end{tabular}
and Aphis gossypii consumed by $4^{\text {th }}$ instar larvae and adults of Scymnus syriacus as a function of initial prey density. 

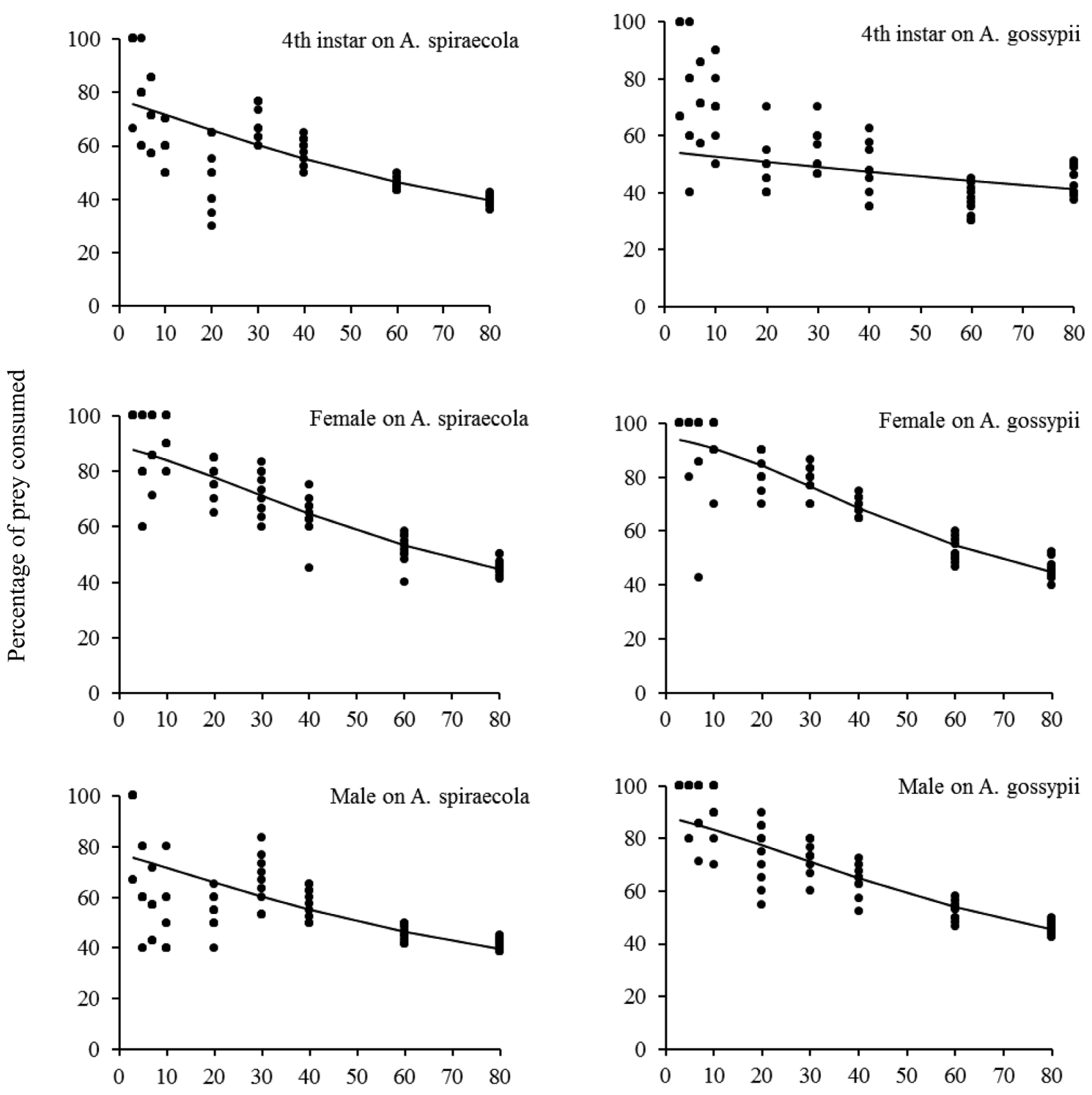

Initial Prey density $(\mathrm{N})$

Fig. 1. Percentage of prey consumed by $4^{\text {th }}$ instar larvae and adults of Scymnus syriacus provided with different densities of Aphis spiraecola and Aphis gossyppi. The data points and solid lines represent the percentage of prey killed and that predicted by the Rogers model, respectively.

\section{RESULTS}

\section{Functional response}

The results of logistic regression analyses of $4^{\text {th }}$ instar larvae and adult males and females of $S$. syriacus to different numbers of $A$. spiraecola and $A$. gossypii are presented in Table 1. In all cases, the linear coefficient was negative $\left(P_{1}<0\right)$, indicating a type II functional response. The results revealed a decline in the proportion of the number of each prey consumed by $S$. syriacus of the initial prey density $\left(N_{e} / N_{0}\right)$ with increase in prey density (Fig. 1).

The attack rate $(a)$ and handling time $\left(T_{h}\right)$ of $4^{\text {th }}$ instar larvae and adult males and females of $S$. syriacus were different for the two species of prey. Attack rate $(a)$ of the different stages of $S$. syriacus fed on $A$. spiraecola varied from 0.0525 to $0.0925 \mathrm{~h}^{-1}$ and the estimated handling time $\left(T_{h}\right)$ ranged from 0.4165 to $0.4985 \mathrm{~h}$ (Table 2). Based on the asymptotic $95 \%$ confidence interval for $D_{a}$, there were significant differences between the attack rate $(a)$ of adult males and adult females, and of adult females and $4^{\text {th }}$ instar larvae (Table 3 ). It shows that the attack rate $(a)$ of adult females of $S$. syriacus on A. spiraecola is higher than that of $4^{\text {th }}$ instar larvae and adult males (Table 3 ). Furthermore, the handling time $\left(T_{h}\right)$ of adult males on $A$. spiraecola was significantly shorter than that of adult females (Table 3 ).

Attack rates $(a)$ of different stages of $S$. syriacus fed on A. gossypii ranged from 0.0328 to $0.1242 \mathrm{~h}^{-1}$ and their handling time $\left(T_{h}\right)$ varied from 0.2365 to $0.5362 \mathrm{~h}$ (Table 2 ). The asymptotic $95 \%$ confidence interval for $D_{a}$ and $D_{T h}$ in pairwise comparison of various stages of $S$. syriacus fed on $A$. gossypii did not include 0 , which means that there were significant differences between the attack rate $(a)$ and handling time $\left(T_{h}\right)$ of various stages of $S$. syriacus (Table 
3 ). Based on the results, adult females and $4^{\text {th }}$ instar larvae of $S$. syriacus had the highest and lowest attack rate $(a)$ on A. gossypii, respectively (Table 2 ). This trend also occurred in the values of handling time $\left(T_{h}\right)$ (Table 2).

Based on the results of pairwise comparisons, there were significant differences between the attack rate $(a)$ of each stage of $S$. syriacus on the two types of prey (Table 3). The attack rates of $4^{\text {th }}$ instar larvae were highest on $A$. spiraecola, whereas those of adult males and adult females were highest on $A$. gossypii (Table 2). Furthermore, the asymptotic $95 \%$ confidence interval for $D_{T h}$ of $4^{\text {th }}$ instar larvae on the two types of prey did not include 0 , which means that there were significant differences between the handling times $\left(T_{h}\right)$ of $4^{\text {th }}$ instar larvae of $S$. syriacus when feeding on $A$. spiraecola and A. gossypii (Table 3). Based on the results, handling times on $A$. gossypii were lower (Table 2).

The highest maximum predation rate $\left(T / T_{h}\right)$ was recorded for adult males feeding on $A$. spiraecola and for $4^{\text {th }}$ instar larvae feeding on $A$. gossypii (Table 2). The values of the coefficient of determination $\left(R^{2}\right)$ indicated that the random predator equation adequately described the functional response of the different stages of $S$. syriacus feeding on both species of prey (Table 2).

\section{No-choice preference}

The mean number of prey consumed by $4^{\text {th }}$ instar larvae and adult females of $S$. syriacus when provided with A. spiraecola or A. gossypii in no-choice experiment is illustrated in Fig. 2. There was a significant difference between the number of prey consumed by $4^{\text {th }}$ instar larvae $(t=$ $-2.961 ; d f=18 ; p=0.008)$. A. gossypii was more preferred than $A$. spiraecola by $4^{\text {th }}$ instar larvae. Furthermore, there was no significant difference in the number of prey consumed by adult females $(t=-0.161 ; d f=18 ; p=0.874)$. Based on these results, the adult females of $S$. syriacus consumed significantly more $A$. spiraecola than the $4^{\text {th }}$ instar larvae $(t=-5.762 ; d f=18 ; p<0.0001)$. However, the consumption of both adult females and $4^{\text {th }}$ instar larvae of $S$. syriacus on $A$. gossypii did not differ significantly $(t=$ $-0.809 ; d f=18 ; p=0.429)$.

\section{Choice experiment and switching}

The mean numbers of prey consumed by $4^{\text {th }}$ instar larvae and adult females of $S$. syriacus at different ratios of $A$. spiraecola and A. gossypii are shown in Table 4. According to the results, $4^{\text {th }}$ instar larvae consumed significantly more $A$. spiraecola and $A$. gossypii at the $50: 30$ and $40: 40$ (A. spiraecola: A. gossypii) ratios. The highest numbers of

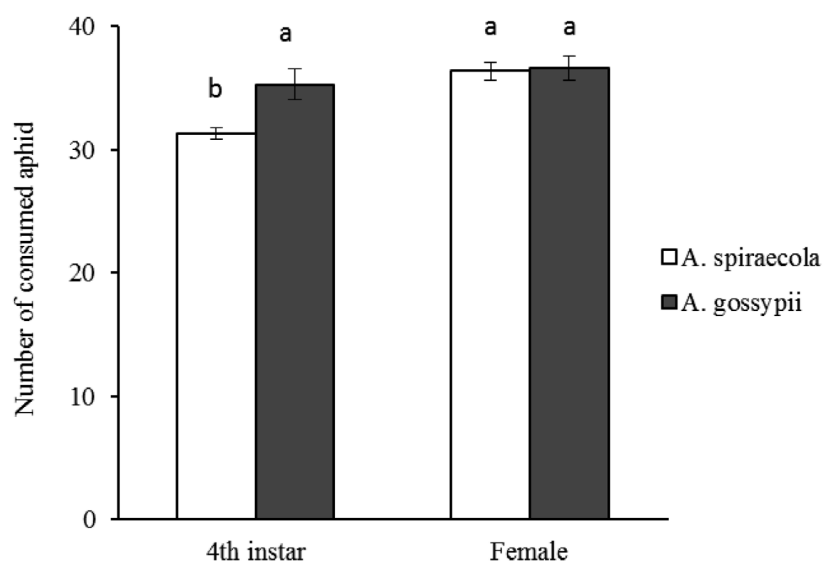

Fig. 2. The mean number of aphids consumed by $4^{\text {th }}$ instar larvae and adult females of Scymnus syriacus provided with Aphis spiraecola and Aphis gossypii for $24 \mathrm{~h}$ in the no-choice experiment. Different letters indicate significant difference between the numbers of aphids consumed by each stage ( $p<0.05$; $t$ test).

A. spiraecola and $A$. gossypii consumed by adult females were recorded at the 50:30 and 30:50 (A. spiraecola:A. gossypii) ratios. At each ratio (except $50: 30$ for adult females), A. gossypii was significantly more preferred by both $4^{\text {th }}$ instar larvae and adult females compared to $A$. spiraecola (Table 4).

When both $A$. spiraecola and $A$. gossypii were offered in equal numbers to the $4^{\text {th }}$ instar larvae and adult females of S. syriacus, the Manly's preference index $\left(\beta_{1}\right)$ was significantly in favour of $A$. gossypii (Table 5). For adult females, the index for other ratios was significantly higher for $A$. gossypii than $A$. spiraecola (Table 5). For $4^{\text {th }}$ instar larvae, the preference index for the 50:30 ratio was higher for $A$. spiraecola and for the $30: 50$ ratio there was no significant preference for either of the two species of aphid (Table 5).

The significant $(F=15.30 ; d f=2,29 ; p<0.0001)$ and negative $\left(\mathrm{y}=-14.47 \mathrm{x}^{3}+11.85 \mathrm{x}-4.56\right)$ non-linear slope for $4^{\text {th }}$ instar larvae and the significant $(F=19.40 ; d f=$ $1,29 ; p<0.0001)$ and negative $(\mathrm{y}=-0.549 \mathrm{x}+0.89)$ linear slope for adult females indicate that for the ratios of prey used, $4^{\text {th }}$ instar larvae and adult females of $S$. syriacus did not switch between $A$. spiraecola and $A$. gossypii.

\section{DISCUSSION \\ Functional response}

The results of functional response studies can determine the success or failure of biocontrol agents in inundative releases (Waage \& Greathead, 1988; Heidarian et al.,

Table 2. Attack rate (a), handling time $\left(T_{h}\right)$, and maximum predation rate $\left(T / T_{h}\right)$ of $4^{\text {th }}$ instar larvae and adults of Scymnus syriacus fed on Aphis spiraecola and Aphis gossypii. ${ }^{*} \mathrm{Cl}-$ Confidence Interval.

\begin{tabular}{|c|c|c|c|c|c|c|c|}
\hline \multirow{2}{*}{ Prey } & \multirow{2}{*}{ Predator stage } & \multicolumn{2}{|c|}{$a$} & \multicolumn{2}{|c|}{$T_{h}$} & \multirow{2}{*}{$T / T_{h}$} & \multirow{2}{*}{$R^{2}$} \\
\hline & & Estimate $\pm \mathrm{SE}$ & $95 \% \mathrm{Cl}^{*}$ & Estimate $\pm \mathrm{SE}$ & $95 \% \mathrm{Cl}$ & & \\
\hline \multirow{3}{*}{ A. spiraecola } & $4^{\text {th }}$ instar & $0.0618 \pm 0.00451$ & $0.0528-0.0707$ & $0.4985 \pm 0.0289$ & $0.4410-0.5560$ & 48.14 & 0.96 \\
\hline & Female & $0.0925 \pm 0.00656$ & $0.0795-0.1055$ & $0.4927 \pm 0.0202$ & $0.4526-0.5328$ & 48.71 & 0.97 \\
\hline & Male & $0.0525 \pm 0.00362$ & $0.0453-0.0597$ & $0.4165 \pm 0.0306$ & $0.3557-0.4773$ & 57.62 & 0.96 \\
\hline \multirow{3}{*}{ A. gossypii } & $4^{\text {th }}$ instar & $0.0328 \pm 0.0030$ & $0.0269-0.0388$ & $0.2365 \pm 0.0585$ & $0.1202-0.3528$ & 101.48 & 0.92 \\
\hline & Female & $0.1242 \pm 0.0088$ & $0.1066-0.1418$ & $0.5362 \pm 0.0161$ & $0.5043-0.5681$ & 44.76 & 0.98 \\
\hline & Male & $0.0898 \pm 0.0054$ & $0.0789-0.1007$ & $0.4737 \pm 0.0177$ & $0.4385-0.5090$ & 50.66 & 0.98 \\
\hline
\end{tabular}


Table 3. The parameters of the combined equation for comparing the attack rate and handling time of $4^{\text {th }}$ instar larvae and adults of Scymnus syriacus feeding on Aphis spiraecola and Aphis gossypii. * $\mathrm{Cl}$ - Confidence Interval.

\begin{tabular}{|c|c|c|c|c|c|}
\hline \multirow{2}{*}{ Treatments } & \multirow{2}{*}{ Parameter } & \multirow{2}{*}{ Estimate } & \multirow{2}{*}{ Standard Error } & \multicolumn{2}{|c|}{ Approximate $95 \% \mathrm{Cl}^{*}$} \\
\hline & & & & Lower & Upper \\
\hline \multirow{2}{*}{ Female / Male (on A. spiraecola) } & $D_{a}$ & -0.0400 & 0.0076 & -0.0552 & -0.0248 \\
\hline & $D_{T h}^{a}$ & -0.0762 & 0.0362 & -0.1475 & -0.0048 \\
\hline \multirow{2}{*}{ Female $/ 4^{\text {th }}$ instar (on A. spiraecola) } & $\mathrm{D}_{\mathrm{a}}$ & 0.0360 & 0.0091 & 0.0180 & 0.0541 \\
\hline & $D_{T h}^{a}$ & -0.0234 & 0.0418 & -0.0592 & 0.1060 \\
\hline \multirow{2}{*}{ Male $/ 4^{\text {th }}$ instar (on A. spiraecola) } & $D_{a}$ & -0.0039 & 0.0062 & -0.0163 & 0.0084 \\
\hline & $D_{T h}^{a}$ & -0.0528 & 0.0496 & -0.1507 & 0.0451 \\
\hline \multirow{2}{*}{ Female / Male (on A. gossypii) } & $D_{a}^{\prime \prime \prime}$ & -0.0344 & 0.0104 & -0.0550 & -0.0139 \\
\hline & $D_{T h}^{a}$ & -0.0625 & 0.0239 & -0.1097 & -0.0153 \\
\hline \multirow{2}{*}{ Female $/ 4^{\text {th }}$ instar (on A. gossypii) } & $D_{a}$ & 0.0914 & 0.0128 & 0.0661 & 0.1167 \\
\hline & $D_{T h}$ & 0.2997 & 0.0529 & 0.1954 & 0.4040 \\
\hline \multirow{2}{*}{ Male / $4^{\text {th }}$ instar (on A. gossypii) } & $D_{a}$ & 0.0569 & 0.0081 & 0.0408 & 0.0730 \\
\hline & $D_{T h}$ & 0.2372 & 0.0539 & 0.1307 & 0.3437 \\
\hline \multirow{2}{*}{$4^{\text {th }}$ instar (on A. gossypii) $/ 4^{\text {th }}$ instar (on A. spiraecola) } & $D_{a}$ & 0.0234 & 0.0061 & 0.0114 & 0.0358 \\
\hline & $D_{T h}^{a}$ & 0.2328 & 0.0693 & 0.0960 & 0.3696 \\
\hline \multirow{2}{*}{ Female (on A. gossypii) / Female (on A. spiraecola) } & $D_{a}$ & -0.0317 & 0.0113 & -0.0540 & -0.0094 \\
\hline & $D_{T h}$ & -0.0436 & 0.0256 & -0.0941 & 0.0070 \\
\hline \multirow{2}{*}{ Male (on A. gossypii) / Male (on A. spiraecola) } & $D_{a}$ & -0.0372 & 0.0069 & -0.0510 & -0.0235 \\
\hline & $D_{T h}$ & -0.0572 & 0.0342 & -0.1248 & 0.0103 \\
\hline
\end{tabular}

2012). In this study, we recorded the functional responses of late instar larvae and adult male and female of $S$. syriacus to different densities of $A$. spiraecola and A. gossypii, because they are much more voracious than early instar larvae (Farhadi et al., 2010). Based on the results, $4^{\text {th }}$ instar larvae and adult males and females of $S$. syriacus exhibit a type II functional response to varying densities of $A$. spiraecola and $A$. gossypii, whereby they kill an increasingly higher proportion of prey as prey density declines. Type II functional response may in part reflect the suitability of a predator for regulating orchard populations of both species of aphids (Bayoumy \& Awadalla, 2018). This type of response is also reported for $S$. syriacus preying on $A$. spiraecola (Sahragard, 1988), Scymnus levaillanti Mulsant on A. gossypii (Işıkber, 2005), Scymnus subvilosus Goeze on Hyaloptera pruni Geoffer (Atlihan \& Guidal, 2009), S. syriacus on A. gossypii (Sakaki \& Sahragard, 2011) and $S$. siriacus preying on Aphis fabae Scopoli (Sabaghi et al., 2011b). A type III functional response to different densities of the third instars nymphs of Aphis craccivora Koch on broad bean, Vicia fabae L. leaves is also reported for $S$. syriacus females (Sabaghi et al., 2011a). This reveals that the species of prey and host plant may affect the functional response of S. syriacus (De Clercq et al., 2000; Sarmento et al., 2007).

To determine the magnitude of the responses, the attack rate $(a)$ and handling time $\left(T_{h}\right)$ were estimated. The attack rate $(a)$ and handling time $\left(T_{h}\right)$ of $4^{\text {th }}$ instar larvae and adult males and females of $S$. syriacus were different when feeding on the two species of prey, which implies that different stages of the predator with similar responses do not necessarily attack or handle both types of prey in a similar way (Bayoumy \& Awadalla, 2018). Attack rate $(a)$ is the rate at which a predator searches for prey. According to the results, the attack rates (a) of adult females foraging for both species of aphids were significantly the highest. Similarly, Sabaghi et al. (2011b) report that adult females of $S$. syriacus exhibit high attack rates $(a)$ when feeding on A. fabae. A higher attack rate $(a)$ means that higher numbers of prey are eaten by predators in a given time interval

Table 4. Mean $( \pm \mathrm{SE})$ number of prey consumed by $4^{\text {th }}$ instar larvae and adult females of Scymnus syriacus provided with different ratios of Aphis spiraecola and Aphis gossypii.

\begin{tabular}{ccccccc}
\hline Predator stage & $\begin{array}{c}\text { Prey ratios } \\
\text { (A. spiraecola: } \text { A. gossypii) }\end{array}$ & A. spiraecola & A. gossypii & $t$ & $d f$ & $p$ \\
\hline $4^{\text {th }}$ instar & $50: 30$ & $22.10 \pm 1.67^{\mathrm{Aa}}$ & $12.30 \pm 1.64^{\mathrm{Bb}}$ & 4.170 & 18 & $<0.0001$ \\
& $40: 40$ & $13.70 \pm 0.79^{\mathrm{Bb}}$ & $21.30 \pm 0.88^{\mathrm{Aa}}$ & -6.418 & 18 & $<0.0001$ \\
& $30: 50$ & $11.10 \pm 1.16^{\mathrm{Bb}}$ & $18.90 \pm 1.24^{\mathrm{Aa}}$ & -4.573 & 18 & $<0.0001$ \\
$F$ & & 20.66 & 12.94 & & & \\
df & & 2,27 & 2,27 & & & \\
$\mathrm{p}$ & & $<0.0001$ & $<0.0001$ & & & \\
Female & $50: 30$ & $26.50 \pm 0.95^{\mathrm{Aa}}$ & $24.50 \pm 0.45^{\mathrm{Ab}}$ & 1.888 & 18 & 0.75 \\
& $40: 40$ & $20.50 \pm 0.71^{\mathrm{Bb}}$ & $25.90 \pm 1.26^{\mathrm{Ab}}$ & -3.703 & 18 & 0.002 \\
$F$ & $30: 50$ & $18.20 \pm 1.14^{\mathrm{Bb}}$ & $34.20 \pm 0.84^{\mathrm{Aa}}$ & -11.276 & 18 & $<0.0001$ \\
df & & 20.10 & 32.69 & & & \\
$\mathrm{p}$ & & 2,27 & 2,27 & & & \\
\hline
\end{tabular}

Means in the same column followed by different lowercase letters are significantly different $(p<0.05$, Tukey test). Means in the same row followed by different uppercase letters are significantly different $(p<0.05, t$ test). 
Table 5. Preference index $( \pm S E)$ of $4^{\text {th }}$ instar larvae and adult females of Scymnus syriacus provided with different ratios of Aphis spiraecola and Aphis gossypii.

\begin{tabular}{|c|c|c|c|c|c|c|}
\hline \multirow{2}{*}{$\begin{array}{l}\text { Predator } \\
\text { stage }\end{array}$} & \multirow{2}{*}{$\begin{array}{c}\text { Prey ratios } \\
\text { (A. spiraecola:A. gossypii) }\end{array}$} & \multicolumn{2}{|c|}{ Preference index } & \multirow[b]{2}{*}{$t$} & \multirow[b]{2}{*}{$d f$} & \multirow[b]{2}{*}{$p$} \\
\hline & & A. spiraecola & A. gossypii & & & \\
\hline $4^{\text {th }}$ instar & $\begin{array}{l}50: 30 \\
40: 40 \\
30: 50\end{array}$ & $\begin{array}{l}0.579 \pm 0.02^{\mathrm{A}} \\
0.356 \pm 0.02^{\mathrm{B}} \\
0.487 \pm 0.03^{\mathrm{A}}\end{array}$ & $\begin{array}{l}0.420 \pm 0.02^{\mathrm{B}} \\
0.643 \pm 0.02^{\mathrm{A}} \\
0.512 \pm 0.03^{\mathrm{A}}\end{array}$ & $\begin{array}{c}4.377 \\
-9.053 \\
-0.527\end{array}$ & $\begin{array}{l}18 \\
18 \\
18\end{array}$ & $\begin{array}{c}<0.0001 \\
<0.0001 \\
0.605\end{array}$ \\
\hline Female & $\begin{array}{l}50: 30 \\
40: 40 \\
30: 50\end{array}$ & $\begin{array}{l}0.309 \pm 0.01^{\mathrm{B}} \\
0.392 \pm 0.02^{\mathrm{B}} \\
0.447 \pm 0.02^{\mathrm{B}}\end{array}$ & $\begin{array}{l}0.690 \pm 0.01^{\mathrm{A}} \\
0.606 \pm 0.02^{\mathrm{A}} \\
0.552 \pm 0.02^{\mathrm{A}}\end{array}$ & $\begin{array}{l}-18.645 \\
-6.676 \\
-2.696\end{array}$ & $\begin{array}{l}18 \\
18 \\
18\end{array}$ & $\begin{array}{c}<0.0001 \\
<0.0001 \\
0.015\end{array}$ \\
\hline
\end{tabular}

Means in the same row followed by different letters are significantly different $(p<0.05, t$ test).

(Jervis \& Kidd, 1996). The larger size of females and their high-energy requirements for producing eggs means that adult females need to attack and consume more prey than other stages (Hodek \& Honek 1996). However, the lower theoretical predation rate $\left(T / T_{h}\right)$ of females recorded in this study are due to their higher handling time $\left(T_{h}\right)$.

Handling time $\left(T_{h}\right)$ is the total time spent by a predator in catching, subduing, killing, eating and digesting prey (Veeravel \& Baskaran, 1997). In this study, adult males and $4^{\text {th }}$ instar larvae were significantly faster in subduing and digesting $A$. spiraecola and $A$. gossypii, respectively. Sometimes, predators that have a short handling time $\left(T_{h}\right)$ may not have a high attack rate $(a)$ (Bayoumy \& Awadalla, 2018). So, the inverse relationships recorded in this study between handling time $\left(T_{h}\right)$ and attack rate $(a)$ in different stages of $S$. syriacus may be due to partial consumption, especially at high prey densities (Hodek \& Honek, 1996; Aljetlawi et al., 2004). That is, subduing and digesting prey did not impede the predator from further searching for or handling prey. Partial consumption can result in a greater reduction in pest abundance. Pairwise comparisons revealed that adult females attacked $A$. gossypii more than A. spiraecola. Based on the lower handling time $\left(T_{h}\right)$ of $4^{\text {th }}$ instar larvae when provided with $A$. gossypii, this stage has higher rates of maximum predation $\left(T / T_{h}\right)$. This is because of the high energy demands of its subsequent non-feeding pupal stage (Hodek \& Honek, 1996). In addition, the shorter handling time $\left(T_{h}\right)$ for $A$. gossypii may be related to its smaller size compared to A. spiraecola (pers. observ.), which makes it more vulnerable to predation (Heydari et al., 2011). It is concluded that $4^{\text {th }}$ instar larvae of $S$. syriacus are likely candidates for use in the biocontrol of $A$. gossypii. Furthermore, adult females could be more efficient if employed against infestations of both aphids in citrus orchards.

\section{No-choice preference}

Prey preference is critical for understanding the population dynamics of predators and their ability to control the abundance of their prey. In addition, in order to optimize the mass rearing of natural enemies for use as biocontrol agents, it is important to know their preferred prey/host (Jervis \& Kidd, 1996). Fourth instar larvae preferred $A$. gossypii to $A$. spiraecola. Furthermore, the number of $A$. spiraecola and $A$. gossypii consumed by adult females did not differ significantly, which indicated that the adult stage did not show a preference for either of these aphids. Butin et al. (2004) demonstrate that Scymnus ningshanensis Yu $\&$ Yao show little preference (in terms of consumption) for different species of adelgids (Adelges tsugae Annand and Adelges cooleyi Gillette or Pineus strobe Hartig), but does not prefer the woolly alder aphid (Paraprociphilus tessellatus Fitch). Limbu et al. (2015) report that Scymnus camptodromus $\mathrm{Yu}$ and Liu shows no preference for either the woolly alder aphid (P. tessellatus) or woolly apple aphid (Eriosoma lanigerum Hausmann) and only a slight preference for A. gossypii in choice and no-choice experiments.

Nutritional quality of aphids for the survival, development, weight gain, egg maturation and oviposition of predators has an important role in the prey preferences of predators (Provost et al., 2006; Jessie et al., 2015). Physiological and morphological status of host plant, predator characteristics such as age, size, hunger level, genetic traits, encounter rate and environmental conditions may also affect the prey preferences of predators (Thompson, 1975; Ferran \& Dixon, 1993; Dixon 1998; Al-Zyoud \& Sengonca, 2004; Provost et al., 2006; Banihashemi et al., 2017). It is possible that these traits influenced the selection of prey by $S$. syriacus in our study. However, the different ability of $4^{\text {th }}$ instar larvae and adult females of $S$. syriacus in handling prey, as mentioned above, as well as different physiological characteristics of aphids may affect the prey preference of the different stages of predators.

\section{Choice experiment and switching}

Switching behaviour is a good strategy for coping with prey scarcity (Hassanzadeh Avval et al., 2018). S. syriacus $4^{\text {th }}$ instar larvae and adult females preferred $A$. gossypii, when two species of aphids were offered in equal proportions. However, this predator, especially the adult females, did not switch their preference from $A$. gossypii to A. spiraecola when the abundance of $A$. spiraecola was increased, indicating a density independent preference. Likewise, working with two coccinellids (Coccinella septempunctata L. and Harmonia axyridis Pallas) and two species of prey (Aphis citricola Van der Goot and Tetranychus urticae Koch), Lucas et al. (1997) does not report switching behaviour as both coccinellids preferred $A$. citricola. The preference for a particular species implies that the predator choose that prey independently of its abundance or accessibility (Keshavarz et al., 2015).

Generally, predators forage for food efficiently and tend to increase their nutritional gain while decreasing the costs and risks associated with predation (Stephens \& Krebs, 
1986). Therefore, when a predator encounters two types of prey it chooses the one most likely to maximize its fitness (higher survival, fecundity, etc.), and net energy gain (Stephens \& Krebs, 1986). In this regard, large prey are more likely to be selected by predators because of their higherenergy content (Soares et al., 2004). The two species of aphids used in our experiments differed in terms of their size, i.e. A. spiraecola is the larger of the two. However, $S$. syriacus preferred the smaller species (i.e. A. gossypii) in the current study. Similarly, Keshavarz et al. (2015) report that the aphidophagous ladybird, Propylea quatuordecimpunctata L. prefers A. gossypii over A. fabae despite the larger size of the latter.

According to Holling (1961), predators spend more time capturing and killing large than small prey, which may decrease their capture efficiency and consumption rate. Schmidt et al. (2012) report that, even when prey size is controlled for, prey quality affects the predator's preference. Other factors such as aphid mobility, its escape behaviour (walking away, kicking), defensive secretion from abdominal cornicles, vulnerability to predators, the aphid's physical structure, such as thickness of its cuticle, length of appendages, overall body size and duration of the experiment may influence the acceptance of particular aphids by predators (Lawton et al., 1974; Crawley, 1992; Eubanks \& Denno, 2000; Nedved \& Salvucci, 2008). Therefore, it is necessary to determine whether and to what extent these features determined $S$. syriacus preference for $A$. gossypii over A. spiraecola in this study.

\section{CONCLUSION}

The results of the current study extend our knowledge on the functional response and prey preference of one of the most important predators of citrus aphids and provide a better understanding of prey-predator interactions. This laboratory study revealed that the $4^{\text {th }}$ instar larvae of $S$. syriacus were more efficient predators of $A$. gossypii and adult females more efficient predators of both $A$. spiraecola and $A$. gossypii. However, we believe that the $4^{\text {th }}$ instar larvae and adult females of $S$. syriacus could act synergistically in controlling the population abundance of both of these aphids in citrus orchards, because $4^{\text {th }}$ instar larvae usually remain longer in patches of aphids, and thus can be very efficient in controlling the abundance of aphids in each patch, while the adults usually fly and disperse actively and thus can find new patches of aphids (Hodek \& Honek, 1996). Therefore, further field-based studies are needed in order to provide more accurate estimates of the biocontrol potential of $S$. syriacus in citrus orchards.

ACKNOWLEDGEMENTS. This research was supported by the University of Mohaghegh Ardabili, Ardabil, Iran, which is greatly appreciated.

\section{REFERENCES}

Alizadeh Kafeshani F., Rajabpour A., Aghajanzadeh S., GholaMIAN E. \& FARKHARI M. 2018: Important predaceous insects of citrus aphids (Hemiptera: Aphididae) in the north of Iran. Iran Agric. Res. 37: 99-104.
Aljetlawi A.A., Sparrevik E. \& Leonardsson K. 2004: Preypredator size-dependent functional response: derivation and rescaling to the real world. - J. Anim. Ecol. 73: 239-252.

AllaWi T.F. 2006: Biological and ecological studies on Scymnus syriacus and Scymnus levaillanti (Coleoptera: Coccinellidae). - Eur. J. Entomol. 103: 501-503.

Al-Zyoud F.A. \& Sengonca C. 2004: Prey consumption preferences of Serangium arcesetosum Sicard (Col., Coccinellidae) for different prey stages, species and parasitized prey. $-J$. Pest Sci. 77: 197-204.

Atlihan R. \& Guidal H. 2009: Prey density-dependent feeding activity and life history of Scymnus subvillosus Goeze (Coleoptera: Coccinellidae). - Phytoparasitica 37: 35-41.

Ayazpour K., Sijam K., Vadamalai G. \& Jaafar H. 2013: Preliminary identification of Citrus tristeza virus (CTV) vectors in Peninsular Malaysia. - Afr. J. Agric. Res. 80: 4128-4133.

Banihashemi A.S., Seraj A.A., Yarahmadi F. \& Rajabpour A. 2017: Effect of host plants on predation, prey preference and switching behaviour of Orius albidipennis on Bemisia tabaci and Tetranychus turkestani. - Int. J. Trop. Insect Sci. 37: 176-182.

BAYOUMY M.H. 2011: Foraging behavior of the coccinellids Nephus includens (Coleoptera: Coccinellidae) in response to Aphis gossypii (Hemiptera: Aphididae) with particular emphasis on larval parasitism. - Environ. Entomol. 40: 835-843.

Bayoumy M.H. \& Awadalla H.S. 2018: Foraging responses of Coccinella septempunctata, Hippodamia variegata and Chrysoperla carnea to changing in density of two aphid species. Biocontr. Sci. Technol. 28: 226-241.

Blackman R.L. \& Eastop V.F. 2000: Aphids on the World's Crops: An Identification and Information Guide. Wiley, London, $467 \mathrm{pp}$.

Butin E.E., Havill N.P., Elkinton J.S. \& Montcomery M.E. 2004: Feeding preference of three lady beetle predators of the hemlock woolly adelgid (Homoptera: Adelgidae). - J. Econ. Entomol. 97: 1635-1641.

Chesson P.L. 1984: Variable predators and switching behavior. Theor. Popul. Biol. 26: 1-26.

Crawley M.J. 1992: Natural Enemies: The Population Biology of Predators, Parasites and Diseases. Blackwell, Oxford, 592 pp.

De Clerce P., Mohaghegh J. \& Tirry L. 2000: Effect of host plant on the functional response of the predator Podisus nigrispinus (Heteroptera: Pentatomidae). - Biol. Contr. 18: 65-70.

Dixon A.F.G. 1998: Aphid Ecology. Chapman \& Hall, London, $300 \mathrm{pp}$.

Emami M.S., Sahragard A. \& Hajizadeh J. 2004: Studies on biology of Scymnus syriacus Marseul (Col., Coccinellidae) in Gilan province. - Pajouhesh Va Sazandegi 17: 17-20 [in Persian].

EnKegaARd A., BrodsgaARd H.F. \& Hansen D.L. 2001: Macrolophus caliginosus: Functional response to whiteflies and preference and switching capacity between whiteflies and spider mites. - Entomol. Exp. Appl. 101: 81-88.

Eubanks M.D. \& DenNo R.F. 2000: Health food versus fast food: the effects of prey quality and mobility on prey selection by a generalist predator and indirect interactions among prey species. - Ecol. Entomol. 25: 140-146.

Farhadi R., Allahyari H. \& Juliano S.A. 2010: Functional response of larval and adult stages of Hippodamia variegata (Coleoptera: Coccinellidae) to different densities of Aphis fabae (Hemiptera: Aphididae). - Environ. Entomol. 39: 1586-1592.

FERRAN A. \& Dixon A.F.G. 1993: Foraging behaviour of ladybird larvae (Coleoptera: Coccinellidae). — Eur. J. Entomol. 90: 383-402.

Garzo E., Soria C., Gomaz-Guillamon M.L. \& Fereres A. 2002: Feeding behavior of Aphis gossypii on resistant accessions of 
different melon genotypes (Cucumis melo). — Phytoparasitica 30: $129-140$.

Hassanzadeh Avval M., Sadeghi-Namaghi H. \& Fekrat L. 2018: Prey preference and prey switching in Anthocoris minki Dohrn (Hemiptera: Anthocoridae). - J. Asia-Pac. Entomol. 21: $1116-1121$

Hassell M. 2000: The Spatial and Temporal Dynamics of Host Parasitoid Interactions. Oxford University Press, Oxford, 212 pp.

Heidarian M., Fathipour Y. \& Kamali K. 2012: Functional response, switching, and prey-stage preference of Scolothrips longicornis (Thysanoptera: Thripidae) on Schizotetranychus smirnovi (Acari: Tetranychidae). - J. Asia-Pac. Entomol. 15: 89-93.

Heydari S., Allahyari H., Farhadi R. \& Fattah-al-Hosseini S. 2011: The effect of temperature on prey preference of adults and fourth instar larvae of Hippodamia variegata (Col: Coccinellidae) on two aphid species, Aphis fabae and Acyrthosiphon pisum (Hem: Aphididae). - Iran. J. Plant Prot. Sci. 42 95-102.

Hodek I. \& HoneK A. 1996: Ecology of Coccinellidae. Kluwer, Dordrecht, $464 \mathrm{pp}$.

HolLING C.S. 1959: Some characteristics of simple types of predation and parasitism. - Can. Entomol. 91: 385-398.

Holling C.S. 1961: Principles of insect predation. - Annu. Rev. Entomol. 6: 163-182.

IȘIKBER A.A. 2005: Functional response of two coccinellid predators, Scymnus levaillanti and Cycloneda sanguinea, to the aphid, Aphis gossypii. — Turk. J. Agric. For. 29: 347-355.

Jaworski C.C., Bompard A., Genies L., Amiens-Desneux E. \& Desneux N. 2013: Preference and prey switching in a generalist predator attacking local and invasive alien pests. $-P L o S$ ONE 8(12): e82231, $10 \mathrm{pp}$.

Jervis M.A. \& KIDD N.A.C. 1996: Insect Natural Enemies: Practical Approaches to Their Study and Evaluation. Chapman and Hall, London, $491 \mathrm{pp}$.

Jessie W.P., Giles K.L., Rebek E.J., Payton M.E., Jessie C.N. \& McCoRnaCK B.P. 2015: Preference and performance of Hippodamia convergens (Coleoptera: Coccinellidae) and Chrysoperla carnea (Neuroptera: Chrysopidae) on Brevicoryne brassicae, Lipaphis erysimi, and Myzus persicae (Hemiptera: Aphididae) from winter-adapted canola. - Environ. Entomol. 44: 880-889.

Juliano S.A. 2001: Non-linear curve fitting: Predation and functional response curves. In Scheiner S.M. \& Gurevitch J. (eds): Design and Analysis of Ecological Experiments. Chapman and Hall, New York, pp. 178-196.

Keshavarz M., Seiedy M. \& Allahyari H. 2015: Preference of two populations of Propylea quatuordecimpunctata (Coleoptera: Coccinellidae) for Aphis fabae and Aphis gossypii (Homoptera: Aphididae). — Eur. J. Entomol. 112: 560-563.

LAWTon J.H., Beddington J.R. \& Bonser R. 1974: Switching in invertebrate predators. In Usher M.B. \& Williamson M.H. (eds): Ecological Stability. Chapman and Hall, London, pp. 141-157.

Limbu S., Cassidy K., Keena M., Tobin P. \& Hoover K. 2015: Host range specificity of Scymnus camptodromus (Coleoptera: Coccinellidae), a predator of hemlock woolly adelgid (Hemiptera: Adelgidae). - Environ. Entomol. 45: 1-7.

Liu Y.Q., Heying E. \& Tanumihardjo S.A. 2012: History, global distribution, and nutritional importance of citrus fruits. Compr. Rev. Food Sci. Food Saf. 11: 530-545.

Loghmanpour Zarini R., Yaghoubi H. \& AKRam A. 2013: Energy use in citrus production of Mazandaran province in Iran. - Afr. Crop Sci. J. 21: 61-65.
Lucas E., Coderre D. \& Vincent C. 1997: Voracity and feeding preferences of two aphidophagous coccinellids on Aphis citricola and Tetranychus urticae. - Entomol. Exp. Appl. 85: 151-59.

LuCK R.F. 1985: Principles of arthropod predation. In Huffaker C.B. \& Rabb R.L. (eds): Ecological Entomology. Wiley, New York, pp. 497-530.

ManLY B.F.J. 1973: A linear model for frequency-dependent selection by predators. - Res. Popul. Ecol. 14: 137-150.

MANLY B.F.J. 1974: A model for certain types of selection experiments. - Biometrics 30: 281-294.

Manly B.F.J., Miller P. \& CooK L.M. 1972: Analysis of a selective predation experiment. - Am. Nat. 106: 719-736.

Murdoch W.W. 1969: Switching in general predators: experiments on predator specificity and stability of prey populations. - Ecol. Monogr. 39: 335-354.

Nedved O. \& Salvucci S. 2008: Ladybird Coccinella septempunctata (Coleoptera: Coccinellidae) prefers toxic prey in laboratory choice experiment. - Eur. J. Entomol. 105: 431-436.

OMKAR \& KUMAR G. 2013: Responses of an aphidophagous ladybird beetle, Anegleis cardoni, to varying densities of Aphis gossypii. - J. Insect Sci. 13: 24, 12 pp.

Provost C., Lucas E. \& Coderre D. 2006: Prey preference of Hyaliodes vitripennis as an intraguild predator: Active predator choice or passive selection? - Biol. Contr. 37: 148-154.

RAJABI G.R. 1986: Insect's Harmful Fruit Trees of Iran. Ministry of Agricultural Research, Education and Extension Organization, Research Institute Pests and Diseases, Tehran, 207 pp.

Rezaei M., Talebi A.A., Fathipour Y., Karimzadeh J. \& MehRABADI M. 2019: Foraging behavior of Aphidius matricariae (Hymenoptera: Braconidae ) on tobacco aphid, Myzus persicae nicotianae (Hemiptera: Aphididae). — Bull. Entomol Res. 109: 840-848.

ROGERS D.J. 1972: Random search and insect population models. - J. Anim. Ecol. 41: 369-383.

Sabaghi R., Sahragard A. \& Hosseini R. 2011a: Area dependent searching efficiency of Scymnus syriacus (Col.: Coccinellidae) feeding on Aphis craccivora (Hem.: Aphididae). - J. Entomol. Soc. Iran 31: 1-16.

Sabaghi R., Sahragard A. \& Hosseini R. 2011b: Functional and numerical responses of Scymnus syriacus Marseul (Coleoptera: Coccinellidae) to the black bean aphid, Aphis fabae Scolopi (Hemiptera: Aphididae) under laboratory conditions. - J. Plant Prot. Res. 51: 423-428.

SABELIS M.W. 1992: Predatory arthropods. In Crawley M.J. (ed.): Natural Enemies: the Population Biology of Predators, Parasites and Diseases. Blackwell, Oxford, pp. 225-264.

SaKaKi S. \& Sahragard A. 2011: A new method to study the functional response of Scymnus syriacus (Coleoptera: Coccinellidae) to different densities of Aphis gossypii. - J. AsiaPac. Entomol. 14: 459-462.

SAHRAGARD A. 1988: Functional response of Symnus syriacus to different densities of Aphis spiraecola. - Entomol. Phytopatol. 1: 42-50 [in Persian].

Sarmento R.A., Pallini A., Venzon M., De Souza O., MolinaRugama A.J. \& Oliveira C.L. 2007: Functional response of the predator Eriopis connexa (Coleoptera: Coccinellidae ) to different prey types. - Braz. Arch. Biol. Technol. 50: 121-126.

Schmidt J.M., Sebastian P., Wilder S.M. \& Rypstra A.L. 2012: The nutritional content of prey affects the foraging of a generalist arthropod predator. - PLoS ONE 7(11): e49223, 9 pp.

Smaili M.C., El Ghadraoui L., Gaboun F., Benkirane R. \& BlenZAR A. 2014: Impact of some alternative methods to chemical control in controlling aphids (Hemiptera: Sternorrhyncha) and 
their side effects on natural enemies on young Moroccan citrus groves. - Phytoparasitica 42: 421-436.

Soares A.N., Coderre D. \& Schanderl H. 2004: Dietary selfselection behaviour by the adults of the aphidophagous ladybeetle Harmonia axyridis (Coleoptera: Coccinellidae). $-J$. Anim. Ecol. 73: 478-486.

Soroushmehr Z., SAhragard A. \& SAlehi L. 2008: Comparative life table statistics for the ladybeetle, Scymnus syriacus reared on the green citrus aphid, Aphis spiraecola, fed on two host plants. - Entomol. Sci. 11: 281-288.

SPSS 2007: SPSS Base 16.0 User's Guide. SPSS Incorporation, Chicago, IL.

Stephens D.W. \& Krebs J.R. 1986: Foraging Theory. Princeton University Press, Princeton, NJ, 247 pp.

TaZerouni Z., Talebi A.A., Fathipour Y. \& Soufbaf M. 2016: Age-specific functional response of Aphidius matricariae and Praon volucre (Hymenoptera: Braconidae) on Myzus persicae (Hemiptera: Aphididae). — Neotrop. Entomol. 45: 642-651.
Tena A. \& Garcia-Mari F. 2011: Current situation of citrus pests and diseases in the Mediterranean Basin. - IOBC-WPRS Bull. 62: $365-378$.

THOMPSON D.J. 1975: Towards a predator-prey model incorporating age structure: the effects of predator and prey size on the predation of Daphnia magna by Ischnura elegans. - J. Anim. Ecol. 44: 907-916.

Van Baalen M., Krivan V., Van RiJin P.C.J. \& Sabelis M.W. 2001: Alternative food, switching predators, and persistence of predator-prey systems. - Am. Nat. 157: 512-524.

Veeravel R. \& Baskaran P. 1997: Searching behaviour of two coccinellid predators, Coccinella transversalis Fab. and Cheilomenes sexmaculatus Fab., on eggplant infested with Aphis gossypii Glov. — Int. J. Trop. Insect Sci. 17: 363-368.

WaAge J.K., Greathead D.J., Brown R., Paterson R.R.M., Haskell P.T., Cook R.J. \& Krishnaiah K. 1988: Biological control: challenges and opportunities. - Phil. Trans. R. Soc. Lond. (B) 318: 111-128.

Received October 1, 2019; revised and accepted January 21, 2020 Published online February 17, 2020 